\section{Sources and sinks of metal contaminants in roadways and water systems: Degraded vehicular wheel weights and residential solders}

\author{
NORA K. FOLEY AND ROBERT A. AYUSO
}

United States Geological Survey

Presenting Author: nfoley@usgs.gov

\begin{abstract}
Vehicular wheel weights and solders are among the most
\end{abstract} important anthropogenic sources of lead contamination in modern society. Characterization of size, shape, and stages of degradation by SEM provides fundamental knowledge of processes related to abrasion, dissolution, and transfer of lead to the surface environment. Our previous [1] and current studies of wheel weights (figs. A-C) and solders (figs. D-F) identified partially abraded and chemically corroded surfaces with reconstituted $\mathrm{Pb}$ particles of litharge $(\mathrm{PbO})$ and/or plattnerite $\left(\mathrm{PbO}_{2}\right)$, and $\mathrm{Pb}$-carbonate and $\mathrm{Pb}$-chloride minerals of acicular needle and hair-like forms $<63 \mu \mathrm{m}$ in size. New geochemical modelling supports the argument that $\mathrm{pH}$ is the most relevant factor in lead solder corrosion; whereas, wheel weights degrade by a combination of abrasion and chemical dissolution. The particle sizes and morphologies identify additional health concerns associated with water derived from house plumbing systems containing $\mathrm{Pb}$ components and with soils located adjacent to roadways.

Degradation of wheel weights or solders can influence the $\mathrm{Pb}$ isotopic composition of local surface water, groundwater, and drinking water. $\mathrm{Pb}$ isotope analysis (TIMS, HR-ICPMS) can identify lead exposure pathways if measurable differences in isotopic ratios exist among potential sources. Lead isotopic ratios for wheel weights and leachates from the U.S. fall along narrow arrays in plots of ${ }^{206} \mathrm{~Pb} /{ }^{207} \mathrm{~Pb}(\sim 1.130-1.230)$ vs. ${ }^{208} \mathrm{~Pb} /{ }^{207} \mathrm{~Pb}$ ( 2.410-2.470). The apparent trend in the ${ }^{208} \mathrm{~Pb} /{ }^{207} \mathrm{~Pb}$ and ${ }^{206} \mathrm{~Pb} /{ }^{207} \mathrm{~Pb}$ plot implicates a lead source from U.S. Mississippi Valley-type deposits combined with a less radiogenic endmember, which may link to an international lead source, such as from deposits in China. The legacy of past and current uses of $\mathrm{Pb}$ in manufactured products will continue to be of global concern for the foreseeable future because $\mathrm{Pb}$-based products, including wheel weights and solders, remain available through primary and secondary global markets. Lead use in industrial, electronic, and consumer products has not decreased significantly since the 1990s. Thus, new and more comprehensive research using geochemical and mineralogical approaches is needed to fully assess the impacts of lead-based manufactured products on lead contamination levels in soils, waters, and other surficial materials.

[1] Ayuso \& Foley (2020) J. Geochem. Expl. 212, 106493.
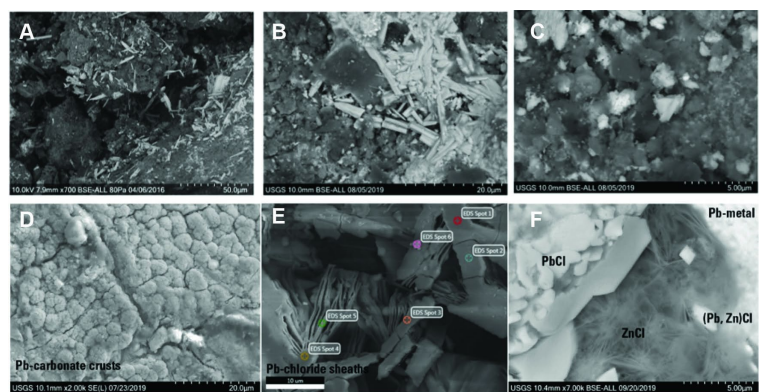